\title{
Simulation of Countercurrent Multi-Effect Drying System
}

\author{
Hong Li, Lianying Wu, Xianli Wu, Yangdong Hu \\ Department of Chemical Engineering, Ocean University of China, Qingdao 266000, China \\ Email: ydhuhd@ouc.edu.cn
}

Received 2012

\begin{abstract}
The paper bulids a countercurrent multi-effect drying process model which can be expressed as a linear programming(LP) problem with the minimum total energy consumption as target function. Based on the model it can be conventient to solve the heat load , degree of drying and other drying parameters of each effect. And it realizes the mathematical simulation an analysis of multi-effect drying process. Such process not only reuses the secondary steam but also utilizes the high energy grade. Drying silica sand using 1-effect drying to 5-effect drying is presented as an example. The energy consumption and energy saving rate are compared by using co-current multi-effect drying and countercurrent multi-effect drying. As a summary, the countercurrent multi-effect drying is better than co-current drying. Considered the equipment investment and energy conservation, the study also concluded that the countercurrent 4-effect drying is the optimum selection, and it can save $57.6 \%$ energy compared to countercurrent 1-effect drying.
\end{abstract}

Keywords: Countercurrent Drying; Multi-Effect Drying; Secondary Steam; LP

\section{Introduction}

Among many process operations in industry, drying is probably one of the most important, as it is common to all sectors of solids processing. Many investigations have shown that drying is an energy intensive operation, which involves complex processes of heat and mass transfer between the product and the drying medium[1-4]. Nowadays, with the situation of energy shortage becoming more and more serious, how to improve the energy utilization efficiency has become a research hot spot. Although a large number of works have been devoted to exploring different features and applications of the thermal drying system, most of those changed the high grade energy to lower grade energy when utilized the waste gas, so a large number of high quality stream latent heat is wasted.

A promising alternative to improve the problem is the use of multi-effect dying system based on the process integration as formulated by Linnhoff[5] and is directed on the efficient use of energy for drying [6-7]. Such a system consists of a number of dryers. By directly utilizing the secondary steam resulting from energy degradation in the drying system, the drying process imports the secondary steam produced by the former effect as the heat source of the following effect thereby reducing energy consumption.

\section{Description the Process of the Countercurrent Multi-Effect Drying}

The countercurrent multi-effect drying process is designed by follow postulated:

(1) Multi-effect drying is a typical batch process.

(2) The dryer is vacuum tray drier. The material is heated by conduction heating(3) The secondary steam is water vapor. In actual operation, it can be recycled by draught fan. Thedraught fan has the function of also dust removal.

(4) Apply secondary steam to heat the wet material indirectly.

(5) The drying materials are not flowing, but by controlling the flowing of secondary steam, the drying materials can be regarded as flowing. It can be operated by simulated moving bed in actual operation.

(6) Dried material is distributed very thinly in the dryers, which increases the heating surface area, giving the drying system better heat transfer effect and efficiency.

(7) Best fit for the drying process that water evaporation process occurs in small particle materials surface.

\subsection{Technological Process}

The countercurrent multi-effect steam drying flowchart is shown in Figure 1. Set the number of total effect as n. Hot fresh vapor enters the last drying room to heat the solid materials in it, while secondary steam discharged from the last drying room $n$ enters the front drying room $n-1$ to heat the solid materials there. Taking the $\mathrm{i}-1, \mathrm{i}, \mathrm{i}+1$ effect drying for example, the secondary steam produced by the $i+1$ effect drying enters the i effect drying room, while the secondary steam produced by the i effect drying enters the i- 1 effect drying room, as so on until the 1 effect drying, the secondary steam produced by the 1 effect drying enters the condenser. The drying materials are not flowing, after the drying material of the i effect drying dried by the secondary steam of the $i+1$ effect drying room produced, this drying room and drying material is regarded as $i+1$ effect drying in the next batch process production cycle.

\subsection{Mathematic Model}

The objective is recycling the second stream energy as a means to minimize the energy consumption of n-effect drying needing. 


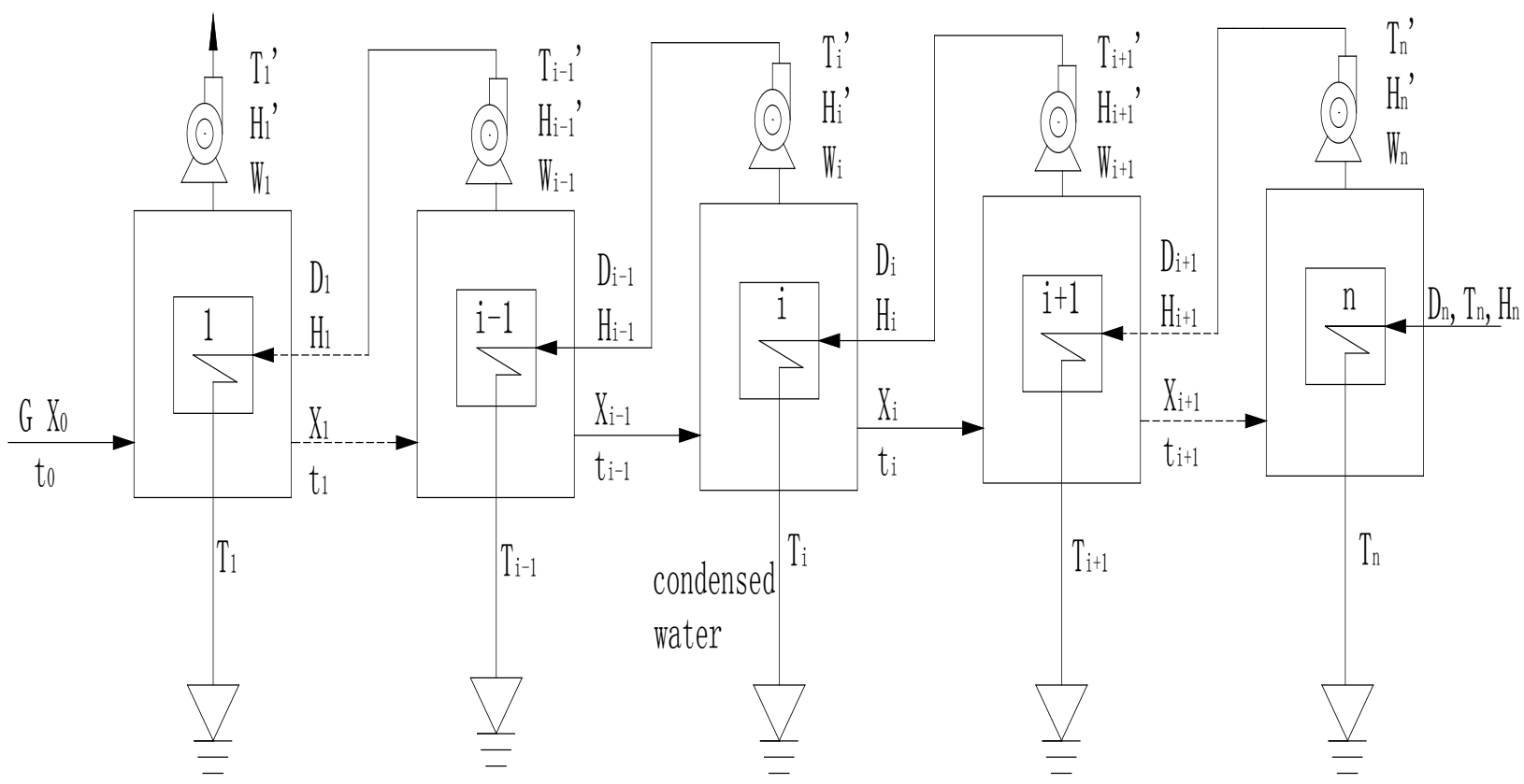

Figure 1. Countercurrent n-effort steam drying process.

$$
\begin{gathered}
\text { Min } \quad Q_{n}=\frac{G c_{s}\left[t_{n}-t_{n-1}\right]+G C\left[t_{n}-t_{n-1}\right] X_{n-1}+G\left[X_{n-1}-X_{n}\right] r_{n}}{\eta} \\
\text { s.t. } \quad D_{i} r_{i} \geq \frac{G C_{s}\left[t_{i}-t_{i-1}\right]+G X_{i-1} C\left[t_{i}-t_{i-1}\right]+G X_{i-1} C\left[t_{i}-t_{i-1}\right]+\left[X_{i-1}-X_{i}\right] r_{i}{ }^{\prime}}{\eta} \\
D_{i}=G\left(X_{i}-X_{i+1}\right) \\
r_{i}=r_{i}{ }^{\prime} \\
0 \leq X_{i}<X_{0} \\
0<i<n
\end{gathered}
$$

The constraint conditions are the moisture material balances and energy balances of each effect drying and the total drying system. The decision variable is $\mathrm{X}_{\mathrm{i}}$.

\subsection{Solving the LP Problem}

The pressure of the countercurrent multi-effect drying system is designed by method of same pressure drop.

$$
\Delta P=\frac{P_{n}-P_{1}^{\prime}}{n}
$$

$\mathrm{P}_{\mathrm{n}}$ and $\mathrm{P}_{1}$ ' are selected according to the actual conditions. Then the temperature and steam enthalpy can be checked from the literature. This paper is in the Matlab environment to solve the linear programming(LP) problem.

\section{Case Study}

This article simulates silica sand n-effect $(1 \leqslant n \leqslant 5)$ drying as example. The parameters of silica sand of n-effect drying is shown in Table 1. The physical parameters of steam are taken from literature [8].

\subsection{Discussion on the Relationship of Drying Effect and Drying Minimum Energy Consumption of n-Effect Drying}

This study simulates the minimum energy consumption from countercurrent 1-effect to 5-effect drying under the same initial and terminal operation conditions. The minimum energy consumption and energy saving rate of n-effect drying compared to 1-effect drying are analyzed. Afterwards the results are compared with the co-current multi-effect drying in the same initial and terminal operation conditions which was calculated in our previous study[9]. All the results are shown in Figure 2 and Figure 3.

As is shown in Figure 2, it can be concluded that the energy consumption of both countercurrent and co-current multi-effect drying decreases with the number of effects. Except 1-effect drying, all the energy consumption of countercurrent n-effect drying is less than that of co-current n-effect drying. 
Also, as shown in Figure 3, the overall energy saving rate for co-current n-effect drying does not increase as dramatically as it does for countercurrent multi-effect drying. Many scholars have concluded that countercurrent drying had the advantage that while the material humidity decreases, the steam's temperature used as heat source increase, the driving force is equilibrium distribution. As a summary, if allowed, the countercurrent multi-effect drying is the best choice.

Got through the countercurrent drying curve of Figure 2 and Figure 3, the minimum energy consumption of countercurrent 1-effect drying is $533.5 \mathrm{~kW}$, 2-effect is $320 \mathrm{~kW}$, and compared to 1-effect the 2-effect energy saving rate is of $40 \%$. However when the number of effect is more than 4 , the energy consumption and energy saving rate curves tend to smooth. Generally, the multi-effect systems are most effective for 3-4 effects, above this number the energy consumption reduction is marginal and probably not sufficient to justify the increase of system complexity. The energy consumption of countercurrent 4-effect drying is $257 \mathrm{~kW}$ and co-current 4-effect drying is 289
$\mathrm{kW}$. The energy saving rate of countercurrent 4-effect drying is $57.6 \%$ and co-current 4 -effect drying is $49 \%$ compared to 1-effect drying.

\subsection{Drying Effect of Countercurrent n- Effect Drying}

This article calculates the removal water of each effect of countercurrent n-effect drying. The energy of countercurrent n-effect drying is provided according to the calculation from Figure 2. Countercurrent 1-effect drying to 5-effect drying are simulated. The results are shown in Table 2.

\section{Conclusions}

The process of countercurrent multi-effect drying is designed by using linear programming method. Both co-current and countercurrent 1-effect to 5-effect drying are simulated by the method. The minimum energy consumption of such multi-effect drying system is less than that of conventional 1-effect drying system. The energy consumption decreases with

Table 1. The parameters of silica sand of countercurrent n-effect drying.

\begin{tabular}{|c|c|c|c|c|c|c|c|c|c|}
\hline parameters & $\mathrm{G} / \mathrm{kg}$ & $\begin{array}{c}\mathrm{X}_{0} / \mathrm{kg} \text { moisture/kg } \\
\text { absolutely dry material }\end{array}$ & $\begin{array}{c}\mathrm{X}_{\mathrm{n}} / \mathrm{kg} \text { moisture/kg } \\
\text { absolutely dry material }\end{array}$ & $\mathrm{t}_{0} /{ }^{\circ} \mathrm{C}$ & $\mathrm{P}_{\mathrm{n}} / \mathrm{kPa}$ & $\mathrm{P}_{1} / \mathrm{kPa}$ & $\mathrm{T}_{\mathrm{n}} /{ }^{\circ} \mathrm{C}$ & $\mathrm{T}_{1}{ }^{\circ} \mathrm{C}$ & $\eta$ \\
\hline date & 1000 & 0.5 & $\leq 0.01$ & 25 & 140 & 30 & 110 & 66.5 & 1 \\
\hline
\end{tabular}

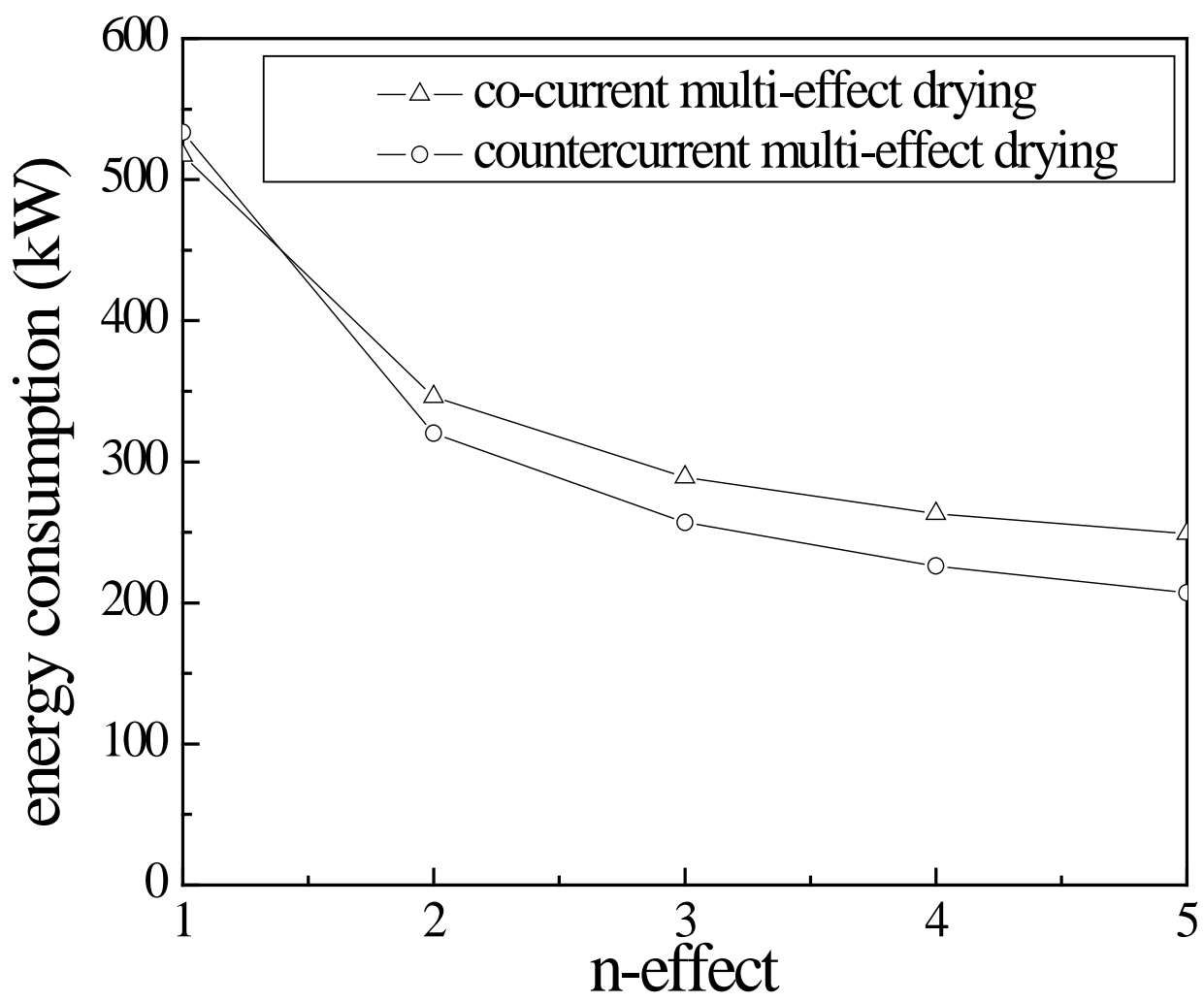

Figure 2. The energy consumption of n-effect drying. 


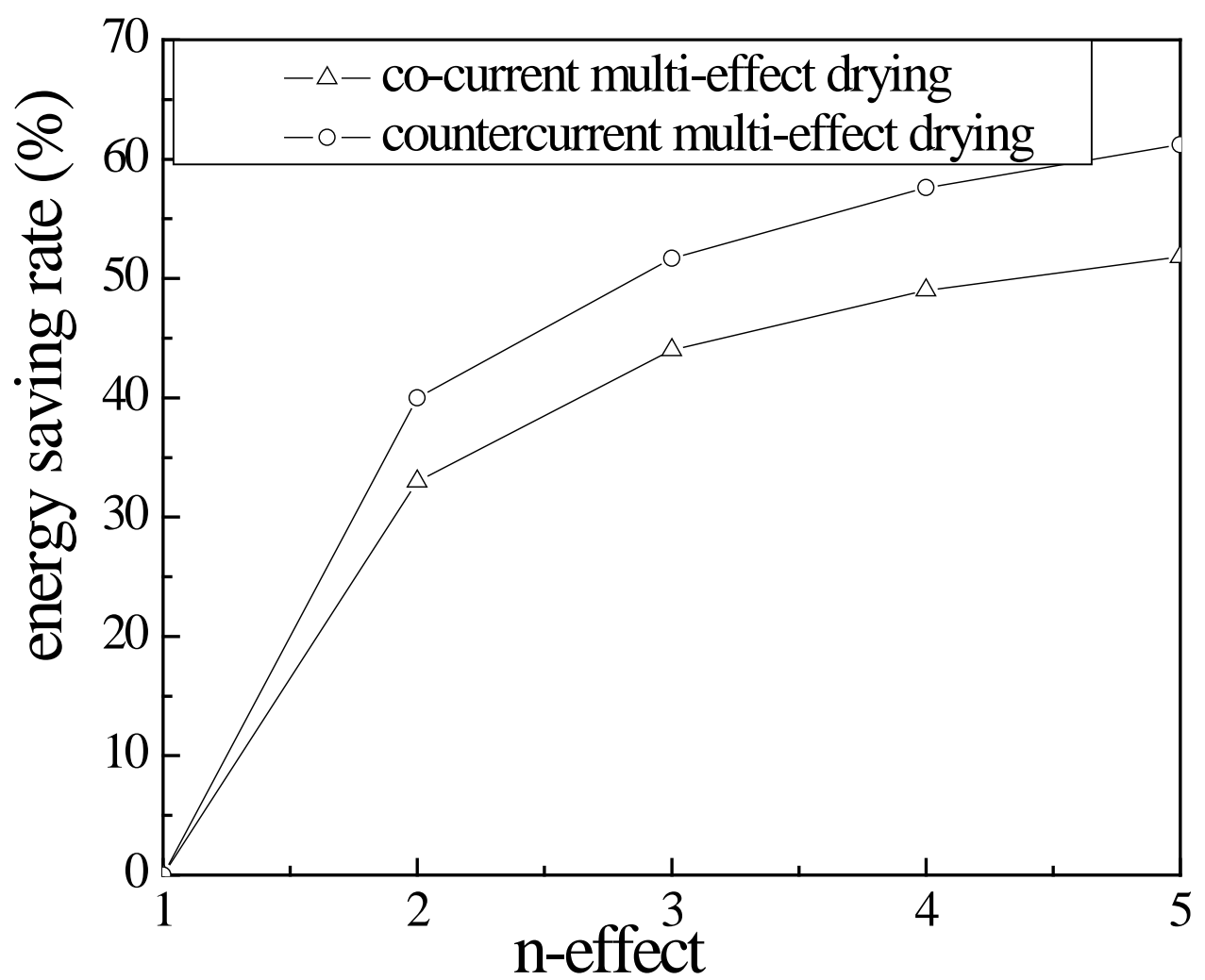

Figure 3. The energy saving rate of n-effect drying.

Table 2. The removal water of each effect of countercurrent n-effect drying.

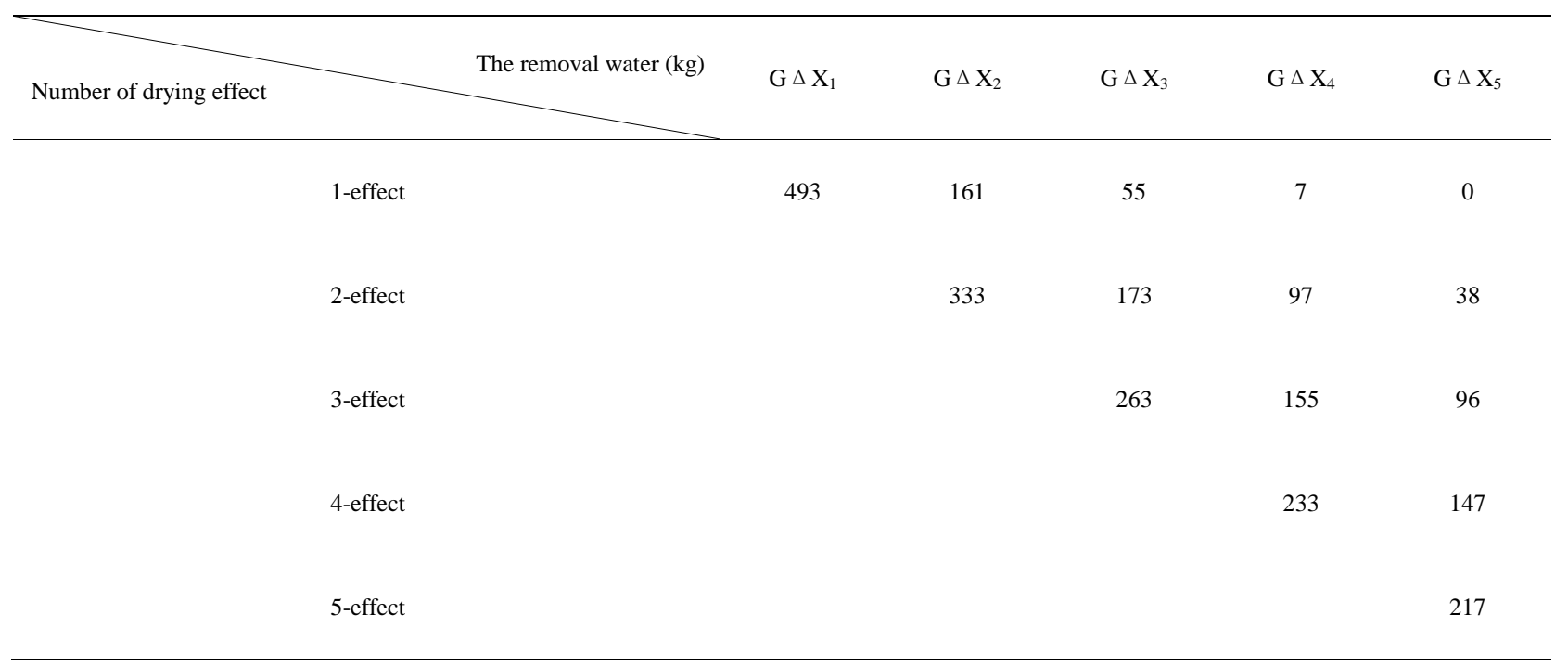

the number of effects. Generally, the multi-effect systems are most effective for 3-4 effects; above this number the energy consumption reduction is marginal and probably not sufficient to justify the increase of system complexity.

Compared with co-current multi-effect drying, the countercurrent multi-effect drying consuming less energy. The energy saving rate of countercurrent 4-effect drying is $57.6 \%$ and co-current 4 -effect drying is $49 \%$ compared to 1 -effect drying. In other words, the energy consumption is halved, which is regarded as a significant step ahead in saving energy.

\section{REFERENCES}

[1] S.K. Chou, K.j. Chua, S.M. Lee, 2003, On the Use of Contact Factor Parameter to Optimize Drying Operations. Energy Conversion and Management. Vol. 44, 1451-1464

[2] I. Dincer, M.A. Rosen, 1999, Environmental and Sustainable Development. Applied Energy. Vol. 46, 427-440 
[3] I. Dincer, A.Z. Sahin, 2004, Incorporation of the Dincer Number into the Moisture Diffusion Equation. International Communications in Heat and Mass Transfer. Vol. 31, 109-119

[4] C.Strumillo,1998, Developments in Drying. Report in Jinan Conference on Drying Technology

[5] Linnhoff, B, 1994, User Guide on Process Integration for the Efficient Use of Energy. The Institution of Chemical Engineering. Rugby, UK

[6] Djaeni, M. Bartels, P. Sanders, J. Straten, G. van. Van Boxtel,
A.J.B, 2007, Process Integration for Food Drying with Air Dehumidified by Zeolites. Drying Technology. 25, 1, 225-239

[7] Krokida, M.K. Bisharat, G. I, 2004, Heat Recovery from Dryer Exhaust Air. Drying Technology, 22, 7, 1661-1674

[8] Yuying Yao, 1999, Principles of Chemical Engineering. Volume one. Tianjing University Press. In Chinese

[9] Li Hong, Hu Yangdong, Zhang Pei, Wu Lianying, Li Yonggang, 2011, Simulation of Co-current Multi-effect Drying System. Advanced Materials Research. 236-238, 808-83 


\section{Nomenclature}

C _ specific heat capacity of water, $\mathrm{kJ} /\left(\mathrm{kg} \cdot{ }^{\circ} \mathrm{C}\right)$

$\mathrm{C}_{\mathrm{s}} \quad$ specific heat capacity of solid, $\mathrm{kJ} /\left(\mathrm{kg} \cdot{ }^{\circ} \mathrm{C}\right)$

$\mathrm{D}_{\mathrm{i}}$ - the amount of secondary steam which is put into the i-effect drying, $\mathrm{kg}$

$\mathrm{G} \quad$ the absolutely dry material feed, $\mathrm{kg}$

$\mathrm{P}_{\mathrm{n}} \quad$ the pressure of the fresh vapor, $\mathrm{kPa}$

$\mathrm{P}_{\mathrm{i}}{ }^{\prime}$ the pressure of the countercurrent i-effect drying, $\mathrm{kPa}$

$\mathrm{t}_{\mathrm{i}}$ the solid temperature of the countercurrent i-effect drying, ${ }^{\circ} \mathrm{C}$

$\mathrm{T}_{\mathrm{n}} \quad$ the temperature of fresh vapor, ${ }^{\circ} \mathrm{C}$

$\mathrm{T}_{\mathrm{i}}$ the steam temperature of the countercurrent i-effect drying import, ${ }^{\circ} \mathrm{C}$
$\mathrm{T}_{\mathrm{i}}{ }^{\text {? }}$ the secondary steam temperature of the countercurrent i-effect drying produces, ${ }^{\circ} \mathrm{C}$

$\mathrm{Q}_{\mathrm{n}} \quad$ - the external energy, $\mathrm{kW}$

$\mathrm{r} \quad$ _ evaporation heat of heating steam, $\mathrm{kJ} / \mathrm{kg}$

r' _ evaporation heat of secondary steam, $\mathrm{kJ} / \mathrm{kg}$

$\mathrm{W}_{\mathrm{i}}$ - the amount of secondary steam that the i-effect drying produces, $\mathrm{kg}$

$\mathrm{X}_{\mathrm{i}} \quad$ dry basis water content of i-effect drying, $\mathrm{kg}$ moisture /kg absolute dry materials

$\eta \quad$ the heat transfer efficiency of each effect drier

i — the i effect

$\mathrm{n} \quad$ total number of drying effect 